\title{
Ausschreibung des Preises für hervorragende Akte auf dem Gebiet der Gesetzgebung 2013
}

Die Deutsche Gesellschaft für Gesetzgebung - vereinigt mit der Gesellschaft für Effizienz in Staat und Verwaltung e.V. (DGG) - verleiht unter der Schirmherrschaft des Bundesministers des Innern und mit finanzieller Unterstützung der Stiftung Apfelbaum - Lernprojekt für Ko-Evolution und Integration - zum vierten Mal den Preis für hervorragende Akte auf dem Gebiet der Gesetzgebung in Höhe von 5.000 (1. Preis), 3.000 (2. Preis) und 2.000 Euro (3. Preis).

Ziel der Auslobung des Preises ist, die Qualität gesetzgeberischer Akte zu fördern. Für die Vergabe des Preises ist von der Deutschen Gesellschaft für Gesetzgebung eine Jury benannt worden. Mitglieder der Jury sind: MR Thomas Hadamek, Leiter des Fachbereichs Parlamentsrecht im Deutschen Bundestag; Jörg Uwe Hahn, Hessischer Minister der Justiz, für Integration und Europa; Prof. Dr. Hans-Günter Henneke, Hauptgeschäftsführer beim Deutschen Landkreistag; Dr. Markus Kerber, Hauptgeschäftsführer des Bundesverbandes der Deutschen Industrie; Prof. Dr. Winfried Kluth, Lehrstuhl für öffentliches Recht der MartinLuther-Universität Halle-Wittenberg; Prof. Dr. Günter Krings MdB, Vorsitzender der Deutschen Gesellschaft für Gesetzgebung e.V.; Dr. Beate Merk MdL, bayerische Staatsministerin für Justiz; Prof. Dr. Andreas Voßkuhle, Präsident des Bundesverfassungsgerichts.

Eingesandt werden können beispielsweise:

- ein gutes Gesetz,

- ein guter Gesetzentwurf oder besonders gelungene Teile eines Gesetzentwurfes,

- ein alternativer Gesetzentwurf,

- ein Gesetzentwurf oder ein Vorschlag zur Vereinfachung eines Gesetzes,

- ein ausgeführter Vorschlag für eine methodische Innovation in der Gesetzgebung,

- eine erfolgreich durchgeführte Gesetzesfolgenabschätzung.

Die Einsendung soll enthalten:

- den preiswürdigen Akt auf dem Gebiet der Gesetzgebung,

- eine kurze Begründung der Preiswürdigkeit,

- den oder die Urheber des Aktes beziehungsweise den möglichen Empfänger des Preises,

- das ausgefüllte Nominierungsformular (erhältlich unter www.dggev.de).

Selbstbewerbungen sind zulässig. Einsendeschluss ist der 31. Mai 2013. Der preiswürdige Akt und die Begründung sind zusammen mit dem Formular in digitaler Form einzureichen. Die Bewerbungen und gegebenenfalls Rückfragen sind an den Vorsitzenden der DGG zu richten. Der Rechtsweg ist ausgeschlossen. 